\title{
Cleveland Clinic Journal of Medicine: Evolution and a look ahead
}

$\mathrm{C}$ leveland Clinic has been publishing a scientific journal for 90 of its first 100 years, contributing to and chronicling our 3 founding missions of better care of the sick, investigation of their problems, and further education of those who serve. ${ }^{1}$ The evolution of the Cleveland Clinic Journal of Medicine (CCJM), the flagship publication of the Clinic, also reflects the stark realities and changes in scientific publication and graduate medical education over the past 4 decades.

Forty years ago, when I was editor in chief of CCJM, I wrote a history of its first 50 years, ${ }^{1}$ which was updated to the first 80 years by the current editor in chief ${ }^{2}$ in 2011! Initially published as the Cleveland Clinic Bulletin in 1931, the Journal became the Cleveland Clinic Quarterly in 1932 and CCJM in 1987. ${ }^{3}$

Republication of articles by Clinic authors from other journals ceased in $1934 .{ }^{1}$ The core of the Journal then became original investigation research articles plus a mix of subject reviews, case reports, editorials, specialty-specific features, letters to the editor, and book reviews. Since 1995 our bread and butter has been timely clinical and bench-to-bedside reviews and practical teaching articles with a focus on continuing medical education, supplanting articles of original investigation research. ${ }^{4}$ Free AMA PRA Category 1 Credit ${ }^{\mathrm{TM}}$ for continuing medical education and maintenance of certification remains a key offering of CCJM. Cleveland Clinic is currently the largest provider of continuing medical education in the United States, in the number of offerings and participants, with CCJM accounting for $27 \%$ of that number (S. Kawczak, e-mail November 2, 2020).

doi:10.3949/ccjm.88a.20187
The Journal has evolved in other ways. In 1983, we expanded our circulation from 16,000 to $40,000.5$ In 1987 , morphing from the Quarterly to CCJM-originally published 10 times a year and now monthly-we further expanded our circulation to $100,000 .{ }^{3}$ In that year, we began accepting advertising and changed the targeted readership focus to general and subspecialty internal medicine, which now includes hospitalists, cardiologists, endocrinologists, pulmonologists, and infectious disease specialists. Currently, print copies of CCJM are received by more than 128,000 readers, and a monthly electronic table of contents alert and a weekly electronic newsletter go out to more than 160,000 . In addition to clinical reviews and editorials, regularly appearing departments now include Symptoms to Diagnosis, 1-Minute Consult, Smart Testing, The Clinical Picture, and Medical Grand Rounds.

CCJM authors are a mix of local, national, and international; nearly half are Cleveland Clinic staff. The CCJM mission statement mandates authors "to identify new findings that are changing the practice of medicine and to advise readers how to apply them in daily patient care. Authors are chosen for their experience, acquired through caring for patients, teaching other physicians, and researching clinical questions" (P. Studer, e-mail September 25, 2020). All articles (except for Medical Grand Rounds) are peer-reviewed by Clinic and external reviewers, with a list of reviewers published annually.

CCJM and its predecessors have published new findings, innovations, and procedure reviews by authorities at the Clinic, ${ }^{2,6}$ including symposia and specialty issues in cardiology,

\section{Cleveland Clinic is 100 years old and has had a medical journal for 90 of those years}


neurology, pediatrics, and dermatology. The Journal currently publishes specialty supplements in cardiology, diabetes, infectious disease, and pulmonary medicine. While claims of attribution may be precarious, the Quarterly published the first use of topical nitrogen mustard in mycosis fungoides (cutaneous T-cell lymphoma) (1959; confirmed in a 1983 commentary $\left.^{6}\right)$, a now-established therapy, and the first 3 cases of acute beryllium pneumonitis as a new occupational disease in the United States (1943; confirmed in a 1983 commen$\left.\operatorname{tary} y^{7}\right)$. The publication on acute beryllium pneumonitis began a quarter-century collaboration of the Clinic with the beryllium industry in Cleveland. Additionally, a major cultural landmark in Cleveland was highlighted in the Quarterly in a detailed, illustrated medical tour through the Cleveland Museum of Art. ${ }^{8}$

Scientific journal editors face a range of issues including disclosure of conflict of interest by authors and reviewers, anonymity of review, timely solicitation and handling of articles with deference to reviewers and authors, and the writing of rejection letters. Additionally, potential misconduct may occur such as dual publication, dual submission, ${ }^{9}$ and plagiarism, whether intentional or not, and CCJM and many other journals now use duplicationdetection software.

The behind-the-scenes editorial and publishing team is the driving engine critical to any journal's smooth operation and survival, no less at CCJM. ${ }^{1,4}$ The Journal has been most fortunate to identify and attract an impressive group of talented and collaborative editors, each with their own unique skills, which significantly improves the final product. They have been gratefully acknowledged with praise in the past, ${ }^{1,4,10}$ and the current cadre is listed on the Journal masthead.

Advertising income is a major lifeblood of controlled circulation journals and has been a cornerstone of CCJM's expanded circulation and frequency since 1987, when CCJM first hired an advertising executive. ${ }^{3,4}$ Syndicated surveys that assess and analyze physician readership are important in ad sales, and those currently performed by Kantar Media show CCJM always ranking high.
Open-access and online publishing are current hot issues in medical research and publishing. CCJM is an open-access journal requiring only registration, with content (text, images, figures, and data) accessible online without financial or technical barriers to readers. Online publishing has evolved in parallel to open-access, with advantages including availability of supplementary material with increased author and reader interaction. The latter comes with links to references, video, and other resources and novel metrics that can assess an article's immediate impact. ${ }^{11,12}$

COVID-19 has had an enormous impact on open access internationally and on the multitude of pandemic-related articles ( $>79,000$ in PubMed in the past year), with journals posting more accepted articles on line ahead of print. Authors are also posting more research articles to preprint servers for timely feedback before submission to a journal for formal peer review. ${ }^{13}$ CCJM has a new practical online series, COVID-19 Curbside Consults, with key clinical, imaging, testing, treatment, and health system practices, authored by clinicians facing the pandemic daily.

A 2019 National Library of Medicine search identified 167 journals that had once been published by hospitals and academic medical centers, but most of them had changed names or ceased publication, and only 6 were currently indexed in MEDLINE. CCJM is 1 of only 2 of the 6 surviving journals that are published monthly (M. Simonson, e-mail August 10, 2019).

In the current environment of electronic and information overload, CCJM is well suited to navigate future challenges. The Journal's major strengths include that it is both owned and published by Cleveland Clinic, and has successfully evolved over the past 90 years while maintaining its scientific excellence, integrity, and editorial independence. We recount the history of CCJM with pride and believe it to be well positioned for success in its next century.

\section{DISCLOSURES}

Dr. Taylor has disclosed owning stock in AstraZeneca, Cigna, Johnson and Johnson, Kao Brands, Merck, and Opko Health. 


\section{TAYLOR}

\section{REFERENCES}

1. Taylor JS. The Cleveland Clinic Quarterly: the first fifty years. Cleve Clin Q 1982; 49(4):142-158. doi:10.3949/ccjm.49.4.149

2. Mandell BF. The Journal at 80 years: 'same as it ever was'-sort of. Cleve Clin J Med 2011; 78(1):8-9. doi:10.3949/ccjm.78b.11001

3. Taylor JS. Cleveland Clinic Journal of Medicine: a new beginning. Cleve Clin J Med 1987; 54(1):1-2.

4. Mandell BF, Clough JD. The people behind the journal really matter Cleve Clin J Med 2016; 83(9):631-632. doi:10.3949/ccjm.83b.09016

5. Taylor JS. Cleveland Clinic Quarterly: a new direction. Cleve Clin Q 1983; 50(1):1.

6. Vonderheid EC, Van Scott E. Commentary and update: topical chemotherapy with mechlorethamine for mycosis fungoides. Cleve Clin Q 1983; 50(2):97-100. doi:10.3949/ccjm.50.2.97

7. Epstein WL. Commentary and update: beryllium granulomas of the skin: a small window to understanding. Cleve Clin Q 1983; 50(2):7375. doi:10.3949/ccjm.50.2.73
8. Borowitz HO. A medical tour through The Cleveland Museum of Art. Cleve Clin Q 1983; 50(4):417-438. doi:10.3949/ccjm.50.4.417

9. Hanke CW, Arndt KA, Dobson RL et al. Dual publication and manipulation of the editorial process. Arch Dermatol 1990; 126(12):16251626. pmid:2256688

10. Clough JD, Mandell BF. Linda Hengstler, publisher, editor, and friend ends 14-year stint at CCJM. Cleve Clin J Med 2002; 69(2):99.

11. Sukhov BA, Burrall B, Maverakis E. The history of open access medical publishing: a comprehensive review Dermatol Online J 2016; 22(9):13030/qt6578w9f8. pmid:28329604

12. Van Noorden R. Open-access Plan $\mathrm{S}$ to allow publishing in any journal. Nature 2020 Jul 16. doi:10.1038/d41586-020-02134-6

13. Flanagin A, Fontanarosa PB, Bauchner H. Preprints involving medical research-do the benefits outweigh the challenges? (editorial). JAMA 2020; 324(18):1840-1843. doi:10.1001/jama.2020.20674

Address: James S. Taylor, MD, Department of Dermatology, A61, Cleveland Clinic, 2049 East 100th Street, Cleveland, OH 44195; taylorj@ccf.org 